\title{
Audit of mother's knowledge of diet in pregnancy and early childhood
}

\author{
J. Brown ${ }^{1}$, M. Alfaham ${ }^{2}$ and D. Tuthill ${ }^{2}$ \\ ${ }^{1}$ Cardiff University School of Medicine, Cardiff, UK and ${ }^{2}$ Children's Hospital For Wales, Cardiff, UK
}

Allergic disease affects one in four of the population in the UK at some time in their lives. The incidence of childhood allergy has been rising since the mid-20th century. The period from mid-gestation until 2 years is important for immune system development and may be influenced by environmental factors including diet. Thus, mother's knowledge of diet during pregnancy and childhood is particularly important. A wide variety of national guidelines by the Food Standards Agency and the British Dietetic Association exist ${ }^{(1-4)}$.

We audited mothers' information sources and their knowledge of diet in pregnancy and early childhood against the current national guidelines.

A questionnaire was devised, based on current national dietary advice during pregnancy and early childhood, which included questions on peanut and caffeine consumption during pregnancy, weaning, the introduction of cow's milk into a baby's diet and vitamin supplements ${ }^{(1-4)}$.

During routine clinic attendance 100 women were interviewed; antenatal clinic (50) and general paediatric clinic (50). The number of mothers using a particular source of dietary advice, and those giving the recognised correct answers are shown in the table below for each group.

\begin{tabular}{lcc}
\hline Info source/advice audited & Antenatal clinic $(n=50)$ & Paediatric clinic $(n=50)$ \\
\hline Midwife & 29 & 25 \\
Health visitor & 1 & 11 \\
Internet & 17 & 9 \\
Mothers can eat peanuts during pregnancy & 1 & 1 \\
Limit coffee intake to 2 cups/d during pregnancy & 15 & 25 \\
Start weaning between 4 and 6 months & 24 & 32 \\
Don't give cow's milk as the main milk source before 1 year & 34 & 47 \\
Give vitamin supplements from 1 to 5 years old & 7 & 13 \\
\hline
\end{tabular}

In conclusion, many mothers are unaware of the current significant nutritional recommendations for diet in pregnancy and early childhood.

1. Food Standards Agency (2008) Agency's Board Recommends Peanut Advice is Revised. http://www.food.gov.uk/news/newsarchive/2008/dec/peanut08

2. Food Standards Agency (2008). http://www.food.gov.uk/news/ pressreleases/2008/nov/caffeineadvice (accessed 16 January 2009).

3. Food Standards Agency (2008). Your baby: Feeding Your Baby in the First Year, http://www.food.gov.uk/multimedia/pdfs/publication/ yourbaby0808.pdf

4. The British Dietetic Association (2008) Vitamin supplements for babies and children, http://www.bda.uk.com/foodfacts/081014BabyChildVitamins.pdf 